\title{
Retraction notice: Influence of compressing pressure on macro void formation carbon monolith for methane adsorption
}

\author{
B.Narandalai ${ }^{1,2 *}$, W.G.Shim ${ }^{2}$, M.S.Balathanigaimani ${ }^{3}$, H.Moon ${ }^{2}$ \\ ${ }^{1}$ Institute of Chemistry and Chemical Technology, Mongolian Academy of Sciences, MAS $4^{\text {th }}$ building, \\ Peace Avenue, Bayanzurkh district, Ulaanbaatar 13330, Mongolia \\ ${ }^{2}$ Department of Advanced Chemicals \& Center for Functional Nano Fine Chemicals \\ Chonnam National University, Gwangju, Korea 61186 \\ ${ }^{3}$ Department of Chemical Engineering, Rajiv Gandhi Institute of Petroleum Technology, Ratapur Chowk, \\ Rae Bareli, 229316 Uttar Pradesh, India \\ *Corresponding author: naran.d10@gmail.com
}

Received: 28 September 2017; revised: 18 December 2017; accepted: 20 December 2017

Copyright $\odot 2017$ B.Narandalai, et al. This is an open access article distributed under the Creative Commons Attribution 4.0 International License CC BY, which permits unrestricted use, distribution, and reproduction in any medium, provided the original work is properly cited

\section{RETRACTION NOTICE}

On 21rd February 2019, the Editorial Board of the Mongolian Journal of Chemistry decided to retract this article entitled "Influence of compressing pressure on macro void formation of carbon monolith for methane adsorption" because of an authorship dispute. The article was originally published in Vol.18 No.44 2017 pp.24-35. doi: https://doi.org/10.5564/mjc.v18i44.934 